\title{
Properties of Frozen Dairy Desserts Processed by Microfluidization of their Mixes ${ }^{1}$
}

\author{
D. W. Olson, ${ }^{\star} †$ C. H. White, ${ }^{\star}$ and C. E. Watson \\ ${ }^{*}$ Department of Food Science and Technology, Box 9805, and \\ fDepartment of Experimental Statistics, Box 9653, \\ Mississippi State University, Mississippi State 39762 \\ †Current affiliation: USDA, Agricultural Research Service, \\ Eastern Regional Research Center, \\ 600 East Mermaid Lane, Wyndmoor, PA 19038
}

\section{ABSTRACT}

Sensory properties and rate of meltdown of nonfat ( $0 \%$ fat) and low-fat ( $2 \%$ fat) vanilla ice creams processed either by conventional valve homogenization or microfluidization of their mixes were compared with each other and to ice cream ( $10 \%$ fat) processed by conventional valve homogenization. Mixes for frozen dairy desserts containing 0,2 , and $10 \%$ fat were manufactured. Some of the nonfat and low-fat ice cream mixes were processed by microfluidization at 50, 100, 150 , and $200 \mathrm{MPa}$, and the remaining nonfat and lowfat ice cream mixes and all of the ice cream mix were processed by conventional valve homogenization at 13.8 $\mathrm{MPa}$, first stage, and $3.4 \mathrm{MPa}$, second stage. The finished frozen and hardened products were evaluated at d 1 and 45 for meltdown rate and for flavor and body and texture by preference testing. Nonfat and low-fat ice creams that usually had a slower meltdown were produced when processing their mixes by microfluidization instead of by conventional valve homogenization. Sensory scores for the ice cream were significantly higher than sensory scores for the nonfat and low-fat ice creams, but the sensory scores for the conventional valve homogenized controls for the nonfat ice cream and low-fat ice cream were not significantly different from the sensory scores for the nonfat ice cream and low-fat ice cream processed by microfluidization of the mixes, respectively. Microfluidization produced nonfat and low-fat ice creams that usually had a slower meltdown without affecting sensory properties.

(Key words: frozen dairy dessert, nonfat ice cream, low-fat ice cream, microfluidization)

Received May 14, 2002.

Accepted July 10, 2002

Corresponding author: D. W. Olson; e-mail: dolson@arserrc.gov.

${ }^{1}$ Approved for publication as Journal Article No. J-10125 of the Mississippi Agricultural and Forestry Experiment Station, Mississippi State University. Research funded in part by the Mississippi Agricultural and Forestry Experiment Station Project No. MIS501020 and by Dairy Management, Inc.
Abbreviation key: HTST = high-temperature shorttime, $\mathbf{M S N F}=$ milk solids-not-fat.

\section{INTRODUCTION}

Concerns of the American consumer that high-fat and low-carbohydrate and fiber diets increase the likelihood of obesity, heart disease, and some forms of cancer have led to the increased study and sale of low-fat and nonfat dairy foods. Frozen dairy desserts, in particular, have the potential for the development of lower-fat products leading to increased sales. In November 2001, 96 million L of low-fat ice cream and 6 million $\mathrm{L}$ of nonfat ice cream were manufactured in the United States (Anonymous, 2002). Since fat provides a desirable texture, mouthfeel, and flavor to many foods, many people are reluctant to switch to a low-fat diet (Drewnowski, 1992). Consumers would likely be satisfied consuming a lowfat diet with the development of nonfat or low-fat products with the body and texture and mouthfeel of higherfat products.

Factors affecting fat perception and mechanisms of fat perception have been investigated. Dairy products containing fat feel creamy since the emulsified fat globules are not individually perceived (Drewnowski, 1992). Glicksman (1991) reported that the combination of organoleptic properties that form the fattiness or oiliness perception in the mouth includes viscosity, lubricity, absorption/adsorption, and possibly cohesiveness, adhesiveness, waxiness, and mouthcoating. Drewnowski (1992) reported that the stimuli of thickness, smoothness, and viscosity are the main oro-sensory cues for fat in milk and cream. The sensory responses to fat occur in stages. Olfactory perception of fat-soluble volatile flavor molecules through the nose or mouth is the first sensory response to fats. The characteristic flavor and aroma of several foods are imparted by these compounds. The detection of food texture by the oral cavity during chewing and salivating determines the subsequent oral perception of fat, but the type of food will 
determine the type of sensation or mouthfeel (Drewnowski, 1992).

Processing at high pressures was believed to improve functional and sensory properties of low-fat and nonfat dairy products, as well as high-fat dairy products. Morgan et al. (2000) produced a 10\% fat ice cream with high sensory scores for creaminess by processing the mix by microfluidization at $120 \mathrm{MPa}$. It was hypothesized that microfluidization can cause low-fat and nonfat milk and dairy products, including frozen dairy desserts, to have a body and texture and mouthfeel more closely resembling their full-fat counterparts. If this hypothesis can be verified, a much greater demand for nonfat and low-fat dairy products could result. If this effect can be accomplished without using fat replacers, demand for these low-fat and nonfat products would be further enhanced. Improving the body and texture quality and body and texture shelf life of dairy products can increase grocery store space and sales.

The objective of this study was to compare the physical and sensory properties of nonfat and low-fat ice creams processed either by microfluidization at high pressures or conventional valve homogenization of their mixes at lower pressure with ice cream processed by conventional valve homogenization of their mixes.

\section{MATERIALS AND METHODS}

\section{Manufacture of Frozen Dairy Desserts}

Pasteurized, unhomogenized skim milk and raw 38\% cream were obtained from the Mississippi State University dairy plant. Mix O Lac (an ingredient containing dry milk solids, dry whey solids, and sugar) was obtained from the John R. White Company (Birmingham, $\mathrm{AL}$ ). Cane sugar (extra fine sugar) was obtained from the Imperial Sugar Company (Sugar Land, TX), and corn syrup solids (24 dextrose equivalents) were obtained from Grain Processing Corporation (Muscatine, IA). Locust bean gum and carrageenan were obtained from Continental Colloids (West Chicago, IL), and natural and artificial vanilla flavor was obtained from Beck Flavors (St. Louis, MO).

Three batches of frozen dairy desserts were manufactured on three separate days. For each batch, appropriate amounts of dry and liquid ingredients were weighed corresponding to percentages presented in Table 1 to give the following compositions. Nonfat ice cream mix was formulated to contain $0 \%$ fat and $13 \%$ milk solids-not-fat (MSNF) giving $32.8 \%$ total solids, and low-fat ice cream mix was formulated to contain $2 \%$ fat and $13 \%$ MSNF resulting in $33.3 \%$ total solids. Ice cream mix was formulated to contain $10 \%$ fat, $11 \%$ MSNF, and $39.2 \%$ total solids. In order to reduce the viscosity of the ice cream mix to allow easier processing
Table 1. Percent by weight of each type of ingredient in the mix of each type of frozen dairy dessert.

\begin{tabular}{lccc}
\hline & \multicolumn{3}{c}{ Frozen dairy dessert } \\
\cline { 2 - 4 } Ingredient & $\begin{array}{l}\text { Nonfat } \\
\text { ice cream }\end{array}$ & $\begin{array}{l}\text { Low-fat } \\
\text { ice cream }\end{array}$ & Ice cream \\
\cline { 2 - 4 } & \multicolumn{3}{c}{$\%$} \\
38\% Cream & 0.00 & 5.26 & 26.32 \\
Skim milk & 73.35 & 69.57 & 50.10 \\
Mix O Lac & 6.60 & 6.64 & 5.18 \\
Cane sugar & 12.50 & 12.00 & 12.00 \\
Corn syrup solids & 7.22 & 6.19 & 6.19 \\
Locust bean gum & 0.22 & 0.22 & 0.11 \\
Carrageenan & 0.11 & 0.11 & 0.11 \\
\hline
\end{tabular}

and freezing, the level of locust bean gum in the ice cream mix was reduced by half compared with the level in nonfat and low-fat ice cream mixes. The liquid ingredients were heated from $4^{\circ} \mathrm{C}$ to between 32 and $43^{\circ} \mathrm{C}$. The dry ingredients were added and mixed with the liquid ingredients. All mixes were pasteurized in a pilot plant high-temperature short-time (HTST) pasteurizer at $82^{\circ} \mathrm{C}$ for $25 \mathrm{~s}$. For the nonfat ice cream mix, the conventional valve homogenizer was pressurized to 13.8 $\mathrm{MPa}$, first stage, and 3.4 MPa, second stage, and the conventionally valve-homogenized samples were then collected for freezing. The conventional valve homogenizer pressure was relieved, and the remaining unhomogenized nonfat ice cream mix was collected for microfluidization. This sequence was also followed for the low-fat ice cream mix. For the ice cream mix, only the conventionally valve homogenized samples for freezing were collected. The unhomogenized nonfat and low-fat ice cream mixes were passed through a M-210EH "Microfluidizer" (Microfluidics International Corporation, Newton, MA) at 50, 100, 150, and $200 \mathrm{MPa}$ with an inlet temperature of 41 to $42^{\circ} \mathrm{C}$, and pressure was increased in an ascending manner. Microfluidized mixes were collected at each pressure.

After aging overnight in a cooler $\left(4^{\circ} \mathrm{C}\right), 5 \mathrm{ml}$ of flavor were added to $3 \mathrm{~L}$ of each type of mix. Mixes were frozen in a 9.46-L Emery Thompson batch freezer (Machine and Supply Co., Bronx, NY). For the nonfat and lowfat ice cream mixes, freezing and whipping on high speed were performed for $2 \mathrm{~min}$ before turning the dasher to low speed. The refrigerant was turned off after $6 \mathrm{~min}$, and samples were collected after $7 \mathrm{~min}$. Ice cream mix was frozen in the same manner except that the dasher was left on high for 7 min instead of 2 min. For each treatment, samples in 0.473 -L containers were collected for sensory evaluation, and samples in 227 -g ice cream cups were collected for meltdown. Frozen samples were placed into a hardening room at $-29^{\circ} \mathrm{C}$ until analysis. 


\section{Rate of Meltdown}

Samples were evaluated for rate of meltdown in duplicate at $\mathrm{d} 1$ and 45 of storage. Samples in cups were transferred from the hardening room to a freezer $\left(-22^{\circ} \mathrm{C}\right)$ at least $24 \mathrm{~h}$ before performing meltdown. A sample was taken out of the freezer, and the block of the frozen dairy dessert was removed from the cup by squeezing the cup. This block was transferred to a weighed-and-tared funnel and beaker. The sample on the funnel and beaker was weighed and then left to melt for 30 min at ambient temperature (approximately 20 to $25^{\circ} \mathrm{C}$ ) on the funnel. The unmelted portion was then removed from the funnel with a spatula and discarded, and the beaker and funnel, now containing the melted portion, was reweighed. Meltdown was expressed as percent melted.

\section{Sensory Evaluation}

Sensory evaluation was performed by a seven-member taste panel. Most of the panelists were trained in evaluating dairy products by participating in or coaching collegiate dairy product judging teams or both. Panelists in private booths were randomly presented samples in randomly numbered cups. The official American Dairy Science Association Intercollegiate Dairy Products Evaluation Contest Score Card for flavor and body and texture for ice cream was used (Marshall and Arbuckle, 1996). The rating of samples was based on quality factors similar to the rating performed by dairy product judging teams. The flavor of each sample was scored once for each replicate on a scale of 1 to 10. A higher number for flavor score indicated a more desirable flavor, and 10 meant no defects. The evaluated defects for flavor included "acid," "cooked," "lacks fine flavor," "lacks flavoring," "lacks freshness," "lacks sweetness," "metallic," "old ingredient," "oxidized," "rancid," "salty," "storage," "syrup flavor," "too high flavor," "too sweet," "unnatural flavor," and "whey." Body and texture of each sample were scored once for each replicate on a scale of 1 to 5 . A higher number for body and texture score indicated a more desirable body and texture, and 5 meant no defects. The evaluated defects for body and texture included "coarse and icy," "crumbly," "fluffy," "gummy," "sandy," "soggy," and "weak." Sensory evaluations were performed on d 1 and 45 of storage.

\section{Statistical Analysis}

Statistical analysis of meltdown. Variations of room temperature during meltdown performed on $\mathrm{d} 1$ versus 45 likely existed. Therefore, storage time was likely confounded with room temperature as a cause for differences in the percentage of meltdown of similarly treated samples performed at different day. As a result, statistical analyses for meltdown on $\mathrm{d} 1$ and 45 were performed separately.

When combining fat and pressure into treatment combinations (treatments), the GLM procedure of SAS version 8.2 (SAS, 1999) was used to analyze meltdown as a randomized complete block design with two subsamples. Treatment was a fixed effect, and block was random. Least squares means were separated using a $t$-test by employing the PDIFF in the GLM procedure.

Statistical analysis of sensory evaluation. When fat and pressure were combined into treatment combinations (treatments), flavor scores and body and texture scores were analyzed using the GLM procedure as a randomized complete block design with a split-plot treatment arrangement (treatment as whole plots and panelist as subplots) with repeated measures at d 1 and 45. Replicate was a random blocking effect, and treatment, panelist, and day were fixed effects.

The least squares means were separated using a $t$ test. The same errors used for testing the null hypotheses were also used as errors for the $t$-test for the differences between the corresponding least squares means.

\section{RESULTS AND DISCUSSION}

\section{Meltdown}

The percentage of meltdown for each treatment evaluated on d 1 and 45 is shown in Figure 1. Treatment for percentage of meltdown performed during d 45 was highly significant $(P<0.01)$. The nonfat and low-fat ice creams processed by conventional valve homogenization of their mixes melted faster $(P<0.05)$ than many of the other treatments.

A possible reason for slower meltdown of low-fat ice cream manufactured by microfluidization instead of conventional valve homogenization of the mixes in the present study can be speculated based on the interaction of fat and protein. As shown for whole milk by transmission electron microscopy (Olson, 2000), many more embedded fat globules within $\mathrm{CN}$ micelles and many more chains and aggregates of proteinaceous material were present after microfluidization than after conventional valve homogenization. If this same postmicrofluidization observation (instead of conventional valve homogenization) of low-fat ice cream also held true, then excessive protein covering of the embedded fat globules may have protected the fat against meltdown leading to less product melting for low-fat ice cream processed by microfluidization, as compared with conventional valve homogenization of the mix. Electron microscopy studies are needed to validate this theory.

Koxholt et al. (2001) found that melting rate of ice cream depended on fat globule size. Ice cream manufac- 


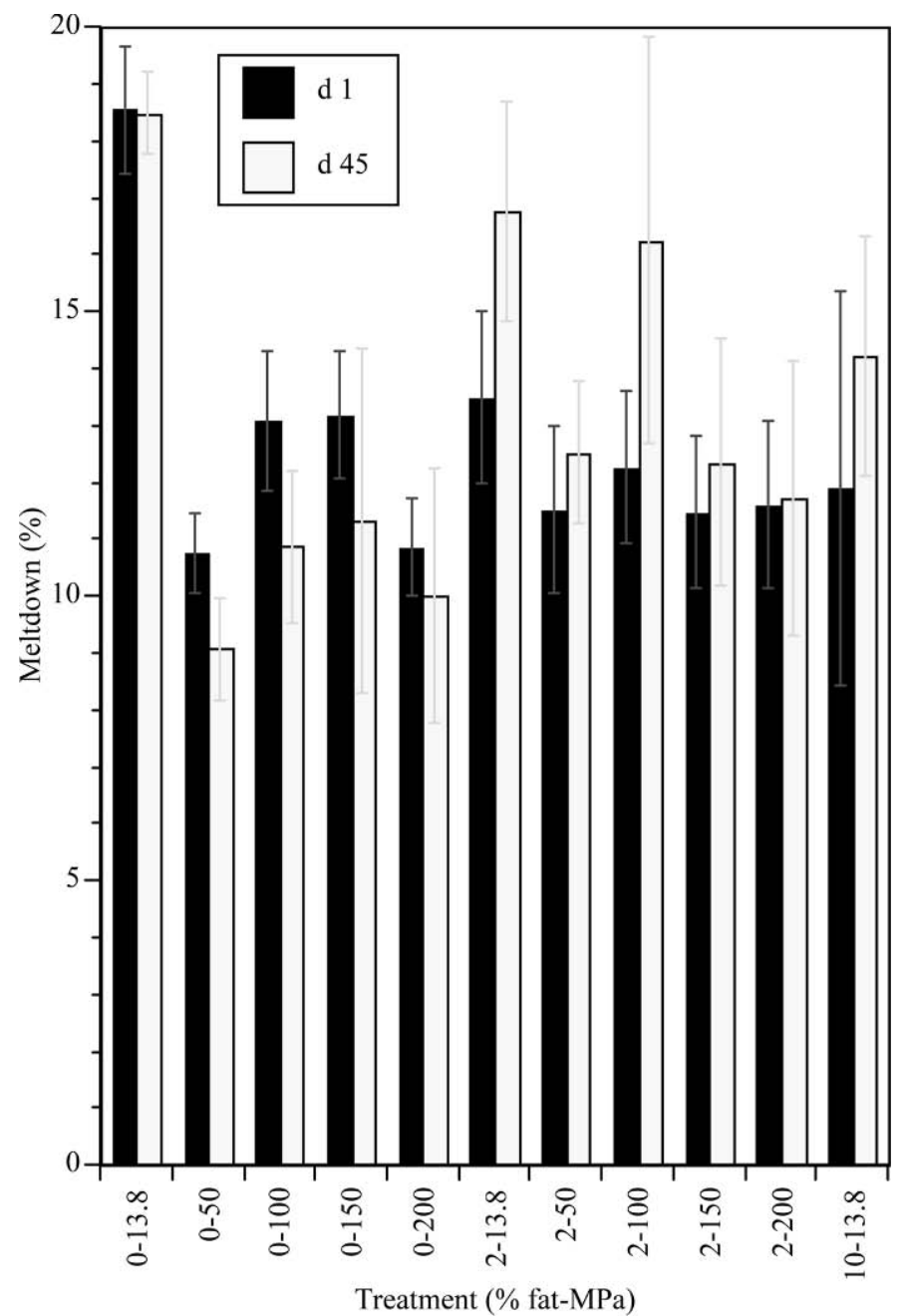

Figure 1. Percent meltdown of frozen dairy desserts (after $30 \mathrm{~min}$ at ambient temperature) performed during $\mathrm{d} 1$ and 45 of storage and associated standard errors as functions of fat content $(0,2$, and $10 \%)$ and conventional valve homogenization pressure (13.8 $\mathrm{MPa})$ and microfluidization pressure $(50,100,150$, and $200 \mathrm{MPa})$.

tured from mix homogenized at 30 and $6 \mathrm{MPa}$ had smaller fat globules and melted faster than ice cream manufactured from mix homogenized at lower pressures. They stated that the foam lamellae retains fat globules larger than the critical diameter but releases smaller fat globules (Koxholt et al., 2001). Although smaller individual colloidal particles (mainly fat globules) in $2 \%$ milk and whole milk were formed after microfluidization than after conventional valve homogenization, chains and aggregates of protein and fat were larger in microfluidized whole milk than in conventionally valve homogenized whole milk when observed by transmission electron microscopy (Olson, 2000). This presence of larger chains and aggregates rather than smaller individual particles could explain the slower meltdown in nonfat and low-fat ice cream processed by microfluidization instead of conventional valve homogenization of the mixes.

Ice cream formulation and differences in ice crystal sizes can affect the rate of meltdown. For frozen dairy desserts processed by conventional valve homogenization of the mixes, the faster meltdown of the frozen dairy desserts with decreasing amounts of fat can be explained by less insulation and less emulsification surrounding air cells normally supplied by fat (Hansen, 1992). Use of stabilizers decreases melting rate (Marshall and Arbuckle, 1996).

Our results disagreed with the results of Campbell and Pelan (1998) and Thomsen and Holstborg (1998) for effect of pressure on melting rate. A faster meltdown of ice cream occurred after increasing homogenization pressure from 2.07 MPa to $13.8 \mathrm{MPa}$ in Campbell and Pelan (1998). However, the melting rate of ice cream in Thomsen and Holstborg (1998) did not vary with conventional valve homogenization pressure between 12 and $20 \mathrm{MPa}$.

\section{Flavor}

The flavor scores for each treatment evaluated on day 1 and 45 are plotted in Figure 2. Panelist, day, and treatment were highly significant $(P<0.0005)$. Flavor scores at 1 were significantly $(P<0.0001)$ higher than flavor scores at d 45. Ice cream had significantly $(P<$ 0.005 ) higher flavor scores than any of the nonfat and low-fat ice creams. Least squares means for flavor scores for low-fat ice cream processed by conventional valve homogenization of the mix were not significantly $(P>0.05)$ different from least squares means for flavor scores for the low-fat ice cream processed by microfluidization of the mix at any pressure. The same trend also occurred for nonfat ice cream.

Many explanations may be given for the lower flavor scores for nonfat and low-fat ice creams compared with ice cream. Since off-flavors can be masked by lipids, it may be more difficult to obtain a desirable flavor in nonfat or low-fat ice creams than in ice cream (Hatchwell, 1994). Another possible explanation could be loss of dairy flavor as fat content decreases (Hansen, 1992). Vanilla dissolves in fat resulting in a slower delivery to the olfactory senses giving a less harsh perception than vanilla dissolved in the aqueous phase (Marshall and Arbuckle, 1996). Also, the higher protein content in nonfat and low-fat ice creams compared with ice cream may have decreased the vanilla flavor perception and led to lower flavor scores (Hansen, 1992). A residual aftertaste may have occurred in nonfat ice cream (Kilara, 1998). 


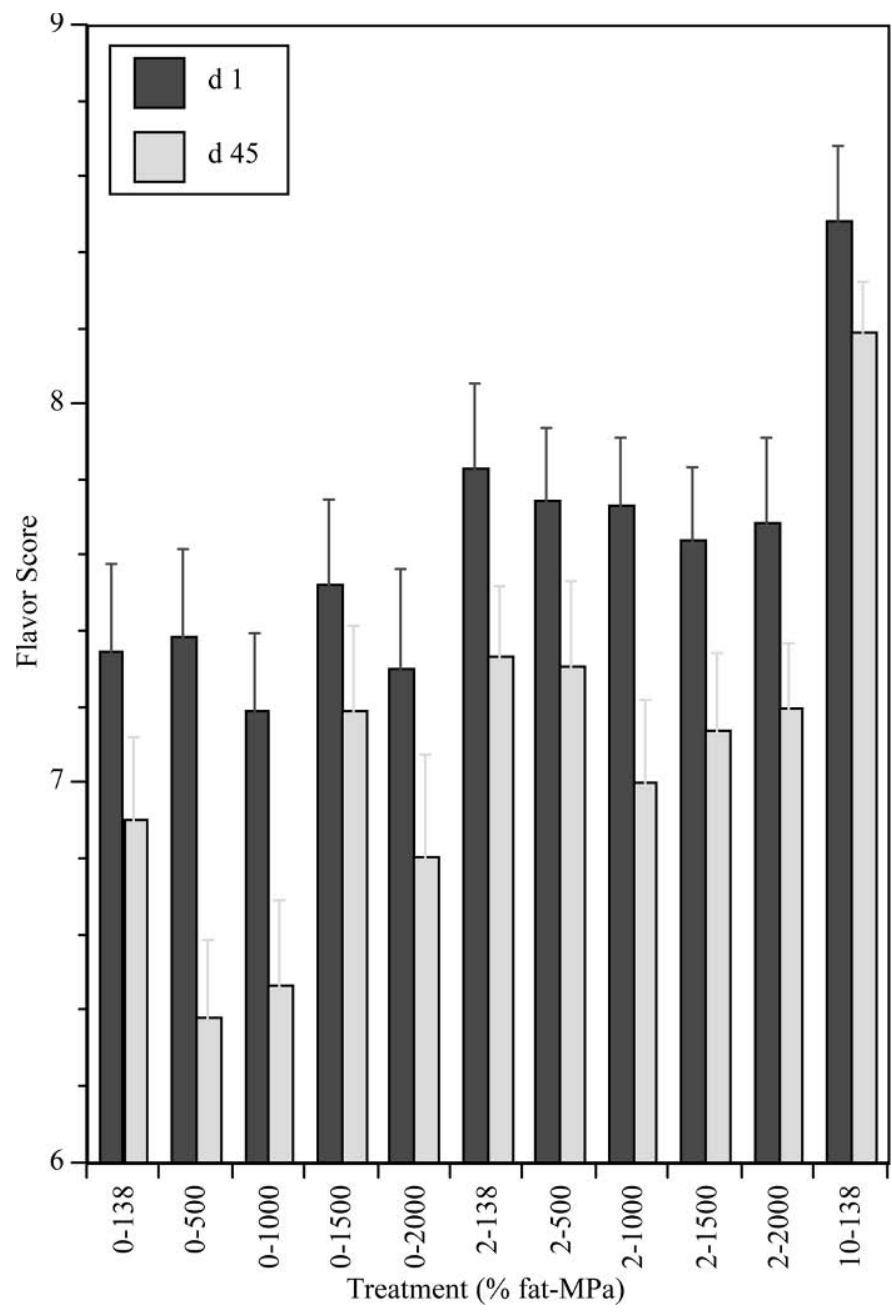

Figure 2. Flavor score (on a 1 to 10 scale in which 10 meant no defects) of frozen dairy desserts and associated standard errors as functions of fat content $(0,2$, and $10 \%)$, conventional valve homogenization pressure $(13.8 \mathrm{MPa})$ and microfluidization pressure $(50,100$, 150 , and $200 \mathrm{MPa}$ ), and $\mathrm{d}$ of storage (1 and 45).

Effect of fat content and storage time on flavor has also been reported in other studies. Roland et al. (1999) found that the sweetness, creaminess, and vanilla flavors were less, but the corn syrup, milk powder, and aftertaste flavors were greater when comparing nonfat ice cream with ice cream. In Conforti (1994), vanilla flavor intensity was not affected by fat content between 10 and $16 \%$ in ice cream. Muncy (1992) reported that flavor scores generally decreased from 0 to $60 \mathrm{~d}$. However, flavor scores of various types of ice cream after $90 \mathrm{~d}$ of storage were equal to or greater than the mean flavor scores for the corresponding treatment after 1 and $30 \mathrm{~d}$ of storage (Lee and White, 1991). Flavor scores for low-fat ice cream did not significantly change between wk 1 and 12 of storage in Baer et al. (1997).

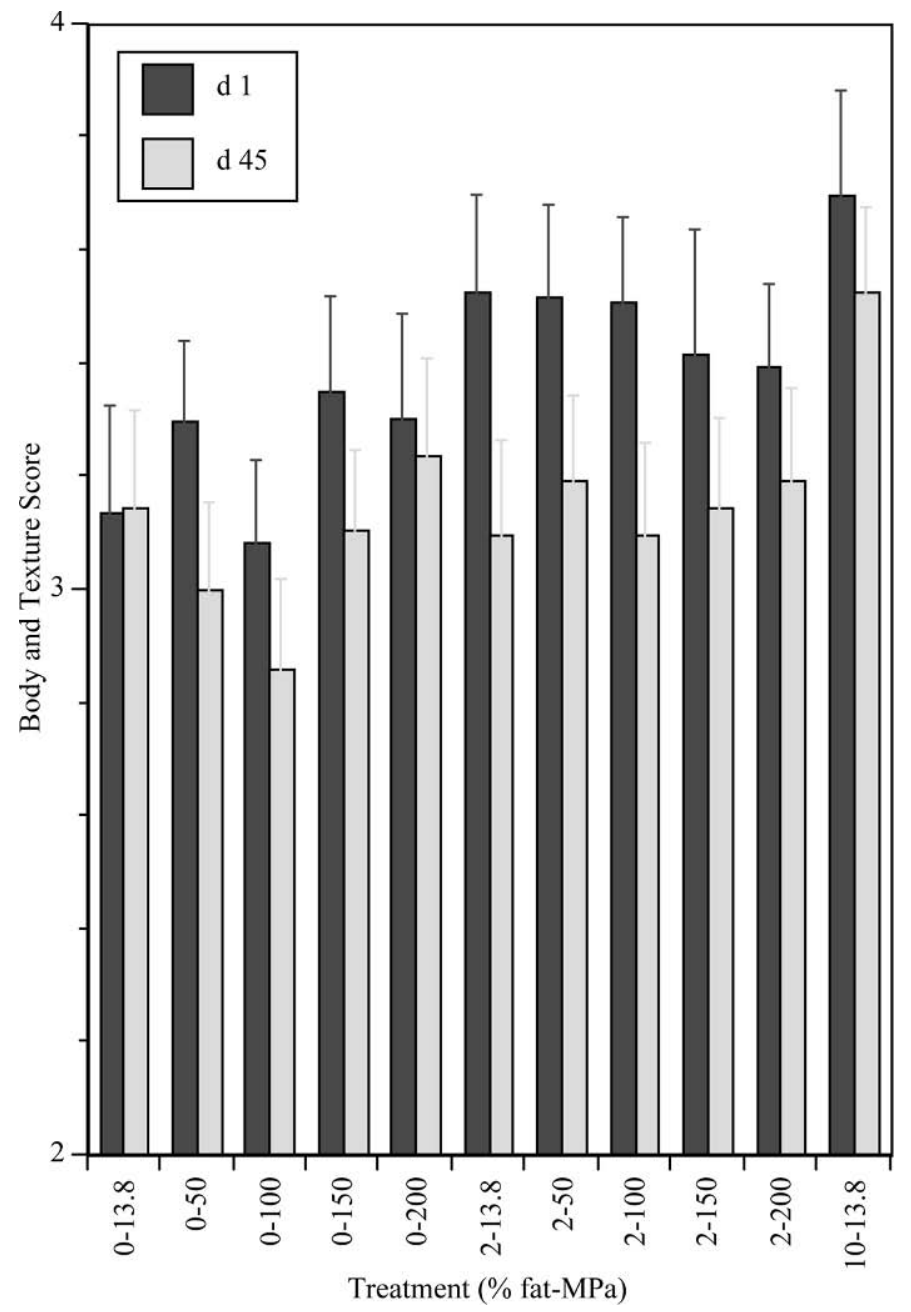

Figure 3. Body and texture score (on a 1 to 5 scale in which 5 meant no defects) of frozen dairy desserts and associated standard errors as functions of fat content $(0,2$, and $10 \%)$, conventional valve homogenization pressure $(13.8 \mathrm{MPa})$ and microfluidization pressure $(50,100,150$, and $200 \mathrm{MPa})$, and $\mathrm{d}$ of storage (1 and 45).

\section{Body and Texture}

Figure 3 displays the body and texture scores for each treatment for $\mathrm{d} 1$ and 45 . Panelist, day, and treatment were significant $(P<0.05)$. Body and texture scores at d 1 were significantly higher $(P<0.05)$ than body and texture scores at $d 45$. The body and texture scores for ice cream were significantly $(P<0.05)$ higher than the body and texture scores of the nonfat and low-fat ice creams except for the low-fat ice cream microfluidized at $50 \mathrm{MPa}(P=0.0620)$. Least squares means for body and texture scores for the low-fat ice cream processed by conventional valve homogenization of the mix were not significantly $(P>0.05)$ different from least squares means for body and texture scores for the low-fat ice creams processed by microfluidization of the mix at 
any pressure. Therefore, an improvement in body and texture of either nonfat ice cream or low-fat ice cream by microfluidization of the mix was not shown in this study.

The lower body and texture scores for low-fat and nonfat ice creams compared with ice cream were not surprising for two reasons. First, lipids and small ice crystals provide smoothness and creaminess to ice cream (Hansen, 1992). Second, a higher water content in low-fat and nonfat ice creams compared with ice cream leads to faster ice crystal growth during hardening, which causes a coarser texture (Hansen, 1992).

Other studies have shown an improvement in the body and texture of low-fat and nonfat frozen dairy desserts. Baer et al. (1997) found that the body and texture of low-fat ice cream were improved by emulsifiers. Body and texture of nonfat ice cream were also improved by prewhipping (Tharp et al., 1992).

The effect of various factors on body and texture and mouthfeel of frozen dairy desserts has been evaluated in many studies. The conventional valve homogenization pressure that the mixes were subjected to in the study of Schmidt and Smith (1988) did not appreciably affect the greasiness of the mouthcoating. A warmer and creamier ice cream was produced by conventional valve homogenization of the mix at $8 \mathrm{MPa}$, compared with 12, 16, or $20 \mathrm{MPa}$ in Thomsen and Holstborg (1998). In Conforti (1994), the body became chewier, and the texture became less icy with increasing fat content between 10 and 16\%. Increasing fat content of frozen dairy desserts from 0.1 to $10 \%$ decreased iciness, meltability, and coldness in Roland et al. (1999).

\section{CONCLUSIONS}

Microfluidization at various pressures affected some properties of frozen dairy desserts. Slower meltdown often occurred in the nonfat and low-fat ice creams processed by microfluidization instead of by conventional valve homogenization of their mixes, and this decreased rate of meltdown may have been due to an excessive protein covering that protected the fat, and therefore the frozen dairy dessert, against meltdown or to the formation of larger chains and aggregates after microfluidization. Highest flavor scores and body and texture scores were obtained for ice cream samples. No significant differences in sensory scores occurred for a given fat content when the mixes were processed by conventional valve homogenization compared to microfluidization at any pressure.

\section{ACKNOWLEDGMENTS}

The funding for this research project by Dairy Management, Inc. is gratefully acknowledged. The authors also thank Julie Wilson for assistance in manufacturing the frozen dairy desserts and Patti Coggins for assistance in performing sensory evaluations.

\section{REFERENCES}

Anonymous. 2002. January 4. National Agricultural Statistics Service, Agricultural Statistics Board, USDA. Washington, D.C. http://usda.mannlib.cornell.edu/reports/nassr/dairy/pdp-bb/ 2002/dary0102.txt.

Baer, R. J., M. D. Wolkow, and K. M. Kasperson. 1997. Effect of emulsifiers on the body and texture of low fat ice cream. J. Dairy Sci. 80:3123-3132.

Campbell, I. J., and B. M. C. Pelan. 1998. The influence of emulsion stability on the properties of ice cream. Page 25 in Ice Cream. Proc. Int. Symp., Athens, Greece, Sep. 18-19, 1997. W. Buchheim, ed. Int. Dairy Federation, Brussels, Belgium.

Conforti, F. D. 1994. Effect of fat content and corn sweeteners on selected sensory attributes and shelf stability of vanilla ice cream. J. Soc. Dairy Technol. 47:69-75.

Drewnowski, A. 1992. Sensory properties of fats and fat replacements. Nutr. Rev. 50:17-20.

Glicksman, M. 1991. Hydrocolloids and the search for the "oily grail". Food Technol. 45(10):94-103.

Hansen, A. P. 1992. Compositional aspects of low-fat frozen dairy desserts. Pages 217-226 in Proc. Penn State Ice Cream Centennial Conf, May 3-6, 1992. M. Kroger, ed. The Pennsylvania State Univ., University Park, PA.

Hatchwell, L. C. 1994. Overcoming flavor challenges in low-fat frozen desserts. Food Technol. 48(2):98-102.

Kilara, A. 1998. Fat mimetics in ice cream and frozen dessert manufacture. Page 65 in Ice Cream. Proc. Int. Symp., Athens, Greece, Sep. 18-19, 1997. W. Buchheim, ed. Int. Dairy Federation, Brussels, Belgium.

Koxholt, M. M. R., B. Eisenmann, and J. Hinrichs. 2001. Effect of the fat globule sizes on the meltdown of ice cream. J. Dairy Sci. 84:31-37.

Lee, F. Y., and C. H. White. 1991. Effect of ultrafiltration retentates and whey protein concentrates on ice cream quality during storage. J. Dairy Sci. 74:1170-1180.

Marshall, R. T., and W. S. Arbuckle. 1996. Ice Cream. 5th ed. Chapman and Hall, New York, NY.

Morgan, D., B. Hosken, and C. Davis. 2000. Microfluidised ice-cream emulsions. Aust. J. Dairy Technol. 55:93.

Muncy, C. A. 1992. The effects of selected stabilizers and milk solid sources on the physical and sensory properties of lowfat and nonfat frozen dairy desserts. M.S. thesis, Mississippi State Univ., Mississippi State, MS.

Olson, D. W. 2000. Properties of milk and frozen dairy desserts processed by microfluidization. Ph.D. dissertation, Mississippi State Univ., Mississippi State, MS.

Roland, A. M., L. G. Phillips, and K. J. Boor. 1999. Effects of fat content on the sensory properties, melting, color, and hardness of ice cream. J. Dairy Sci. 82:32-38.

SAS User's Guide: Statistics, Version 8 Edition. 1999. SAS Inst., Inc., Cary, NC.

Schmidt, K. A., and D. E. Smith. 1988. Effects of homogenization on sensory characteristics of vanilla ice cream. J. Dairy Sci. 71:46-51.

Tharp, B. W., T. V. Gottemoller, and A. Kilara. 1992. The role of processing in achieving desirable properties in health-responsive frozen desserts. Pages 227-246 in Proc. Penn State Ice Cream Centennial Conf. May 3-6, 1992. M. Kroger, ed. The Pennsylvania State Univ., University Park, PA.

Thomsen, M., and J. Holstborg. 1998. The effect of homogenization pressure and emulsifier type on ice cream mix and finished ice cream. Page 105 in Ice Cream. Proc. Int. Symp., Athens, Greece, Sep. 18-19, 1997. W. Buchheim, ed. Int. Dairy Federation, Brussels, Belgium. 